\title{
LA CONFIANZA POLÍTICA EN FIDEL CASTRO. ALGUNAS NOTAS
}

\section{POLITICAL TRUST ABOUT FIDEL CASTRO. SOME NOTES}

\section{Manuel de Jesús Verdecia Tamayo*}

\section{RESUMEN}

El presente artículo desarrolla una propuesta de análisis de la confianza política a partir de su presencia en un conjunto de formulaciones, contenidas en el pensamiento de Fidel Castro, mediante el método hermenéutico con el objetivo de revelar el aporte de dicho líder al tema. De este modo, se contribuye a universalizar el estudio de la confianza política al ampliarse su visión desde la perspectiva revolucionaria del dirigente cubano.

PALABRAS CLAVE: FIDEL CASTRO * REVOLUCIÓN * CUBA * CONFIANZA* POLITICO

\section{ABSTRACT}

The present article develops a proposal of analysis of the political trust from its presence in a set of formulations, contained in the thought of Fidel Castro, by means of the hermeneutical method with the objective of revealing the contribution of this personality to the subject. In this way, it contributes to universalize the study of political trust by broadening the vision of it from the revolutionary perspective of the Cuban leader.

KEYWORDS: FIDEL CASTRO * REVOLUTION * CUBA * TRUST * POLITICIAN 


\section{NOTAS INTRODUCTORIAS}

El tema de la confianza política suscita, cada vez más, la atención de ciudadanos, periodistas, políticos y analistas. Además, se intenta explicar por las ciencias sociales donde su tratamiento resulta compartido entre la Psicología, la Filosofía, la Ciencia Política y la Sociología Política; lo que sugiere la asunción de un enfoque inter $y$ multidisciplinario en su análisis. Los mayores desarrollos se generan desde la Ciencia Política norteamericana donde deviene un concepto crucial (Wilson y Eckel, 2006, p. 189).

Los resultados alcanzados muestran altas cotas de divergencia, entre otras razones por: a) la existencia de profusión e indeterminación conceptual de la confianza política en irrupciones de Miller (1974), Hetherington (1998), Newton (2001), Poppe (2004), Rudolph y Evans (2005); b) el predominio de la disgregación respecto a los objetos orientadores asumidos en los análisis (gobiernos, sistemas políticos, líderes, instituciones, entre otros) por Warren (1999), Klingemann (1999), Hetherington (1999 y 2009), Putnam (2000), Norris (2011), Marien y Hooghe (2013), Braun y Hutter (2016), Zmerli y van der Meer (eds.) (2017).

Esta divergencia posee como sustrato la concepción de la confianza política a partir de un enfoque unilateral sin tener en cuenta su riqueza epistémica y naturaleza procesal, determinada por múltiples factores sociales, culturales, políticos y psicológicos que se relacionan, interrelacionan y condicionan manifestándose hacia diversos objetos orientadores, a partir de las relaciones políticas establecidas por los sujetos que depositan su confianza.

Además, persiste el disenso respecto a sus fuentes y componentes básicos como conjunto esencialmente sistémico y múltiple (Dogan, 1997; Paramio, 1998; Montero y Torcal, 2000; Catterberg y Moreno, 2003; Montero, Zmerli y Newton, 2008; Marien y Hooghe, 2013; Zmerli y van der Meer (eds.), 2017); como también la pluralidad en los marcos teóricos propuestos para su investigación (Mishler y Rose, 2001; Schoon y Cheng, 2011).

La profusión y extensión de la perspectiva democrático liberal portadora de avances cognitivos no despreciables, que jerarquiza la atención en la confianza política resultante de las normas, relaciones e instituciones del sistema representativo, muestra insuficiencia en la formulación de propuestas alternativas al enfoque predominante, necesarias para que el estudio de la confianza política alcance pluralidad $y$ universalidad.

Por ello, se impone como demanda gnoseológica, el tratamiento de la confianza política en nuevos desarrollos teóricos que porten visiones afines con la teoría y la práctica política, vinculadas con el funcionamiento revolucionario de la democracia con orientación popular en la participación política, por cuanto el apoyo del pueblo deviene crucial para la estabilidad y desarrollo del proyecto sociopolítico en cierne.

Cuba constituye una nación donde se construye un modelo de democracia con orientación popular. Aunque en este país, el término "confianza política", no resulta utilizado de forma extendida en el ámbito académico ni en el cotidiano, sí alcanza marcada presencia en las relaciones políticas, la práctica política revolucionaria y en el pensamiento político de los principales líderes, especialmente en el de Fidel Castro Ruz (Verdecia, 2010).

Este artículo desarrolla una propuesta de análisis de la confianza política a partir de su presencia en un conjunto de formulaciones, contenidas en el pensamiento de Fidel Castro Ruz, con el objetivo de revelar el aporte de dicho líder al tema. De este modo, se contribuye a universalizar el estudio de la confianza política al ampliarse su visión desde la perspectiva revolucionaria del dirigente cubano.

En el presente trabajo se utilizó el método hermenéutico. Se aplicó en 206 fuentes conformadas por discursos, entrevistas, informes, manifiestos, reflexiones $y$ artículos contentivos del pensamiento de Fidel Castro, las que resultan sintetizadas en las referencias seleccionadas. Las fuentes revisadas provienen de sitios digitales, editoras y periódicos oficiales del Partido Comunista de Cuba y del Estado cubano, tales como: Granma, www.cuba.cu/gobierno, la Editora Política, entre otros. Estas fuentes se organizan siguiendo el orden lógico del esquema trazado por la persona investigadora atendiendo 
a cada acápite tratado en el artículo; en el análisis se privilegia el contenido fenomenológico alcanzado por la confianza política en el pensamiento, objeto de estudio, enfatizando en la importancia de la confianza política para la toma del poder político y en cómo se proyecta el pensamiento de Fidel Castro hacia la confianza política una vez tomado dicho poder.

\section{NOTAS ESENCIALES}

En el pensamiento de Fidel Castro, a los factores subjetivos se les concede una importancia esencial para la lucha política y la realización de los cambios históricos, por cuanto constituyen: “(...) ingredientes imprescindibles de la historia, de los avances históricos, o de la prolongación de sistemas inicuos, explotadores... que subsisten hasta que una crisis... los hunde definitivamente" (Castro, 1999a, p. 2).

Aunque, Fidel asume la fórmula marxista de la correlación entre los factores subjetivos y las condiciones objetivas, en el análisis para establecer la estrategia de lucha política revolucionaria, aporta el papel dinámico de los factores subjetivos $y$ la posibilidad que a partir de determinadas condiciones puedan activarse $y$ desempeñar un papel determinante:

Pero no hay situación social y política, por complicada que parezca, sin una salida posible. Cuando las condiciones objetivas están dadas para la revolución, ciertos factores subjetivos pueden jugar entonces un papel importante en los acontecimientos. Eso ocurrió en nuestro país... (Castro, 1975, pp. 24-25).

La confianza política destaca, en el pensamiento de Fidel Castro, como uno de los factores subjetivos imprescindibles para la lucha política, no solo para acceder al poder político sino para mantenerlo. En Castro (1985c), la confianza política se construye sobre la base de la interconexión de condicionamientos subjetivos, vinculados con la realidad objetiva y que el líder enuncia al decir: “...una fe política, tiene que fundarse en el razonamiento, en el desarrollo del pensamiento y en el desarrollo del sentimiento; son dos cosas inseparables" (p. 113).
Para luego añadir, en su caso específico: "...tuve otro tipo de valores: una creencia política, una fe política que tuve yo que forjarme por mi propia cuenta, a través de todas mis experiencias, de mis razonamientos $y$ de mis propios sentimientos" (Castro, 1985c, p. 156). Al tomar estas formulaciones como base puede asumirse que la confianza política está configurada por tres componentes básicos: cognoscitivo, afectivo y valorativo-conductual.

El componente cognoscitivo está conformado por los conocimientos, la información y las creencias que determinan la manifestación de la confianza en las relaciones políticas. Se expresa en el sistema de ideas, principios, concepciones y postulados políticos generales que, una vez asimilados por el sujeto social, le permiten explicar y fundamentar, racionalmente, la seguridad hacia objetos, procesos y fenómenos políticos que intervienen en su vida cotidiana (Miller, 1974; Hetherington, 1999 y 2009).

La información desempeña un rol determinante en la fijación y reproducción de la confianza política, los datos influyentes en la creación de dicha confianza no se reciben de la realidad sociopolítica ordenados ni clasificados; además, su búsqueda y actualización se hace esquiva, en tanto una buena parte de los procesos políticos no pueden observarse in situ por la inmensa mayoría de la sociedad que, en su vitalidad, hace imposible el escrutinio cotidiano de los ciudadanos a sus autoridades. Los elementos anteriores y otros, indican la posibilidad de manipulación de los conocimientos para conformar un buen juicio de confianza, en la esfera política (Hetherington, 2009; Montero y Torcal, 2000).

El componente afectivo se refiere al carácter emocional de la relación producida entre el que confía y lo confiado en política, permite reflejar las vivencias de agrado o desagrado, de apoyo o condena. Contiene las emociones, los sentimientos $y$ otras variantes como los estados de ánimo, encargados de matizar durante períodos cortos, prolongados o estables, ciertos procesos psíquicos que condicionan la confianza en la actividad política. Este componente está estrechamente ligado con la evaluación del objeto de la confianza, y trae consigo el 
compromiso, la lealtad y la participación real en los asuntos políticos (Marien y Hooghe, 2013; Newton, 2001).

El componente valorativo-conductual expresa el proceso a través del cual el individuo, los grupos, los sectores y las clases - como resultado de su reflejo subjetivo de la realidad, de sus intereses y cuando la idea de lo digno de confianza política pasa a formar parte de su ideología-, orientan sus acciones y se convierten en una fuerza material, en tanto apoyan, participan activamente $y$ toman decisiones, a través de su reacción política ante determinados objetos, procesos y fenómenos políticos que intervienen en su vida cotidiana. Asumen un comportamiento político de confianza o desafección frente a personas, situaciones, ideas y objetos concretos (Zmerli y van der Meer (eds.), 2017; Schoon y Cheng, 2011).

Se refiere a las tendencias de conducta que producen acciones para cooperar $y$ apoyar al objeto de la confianza, o por el contrario, para reprimirlo o rechazarlo. Este componente incluye acciones abiertas $y$ expresiones verbales referentes a la conducta. Los componentes de la confianza política se integran de manera sistémica, tanto en el plano individual como en el colectivo, por cuanto forman parte de la vida espiritual de toda sociedad, se concretan en la conducta asumida por los diversos actores en relación con múltiples problemáticas y fenómenos de la actividad política. El componente afectivo ocupa el papel rector en tanto está ligado a la evaluación del objeto de la confianza política y orienta el comportamiento a seguir respecto a él.

En el caso de Fidel Castro, debe precisarse que no se trata de un académico o científico, estrictamente, sino de un político en el ejercicio del poder; de ahí que para revelar el aporte de dicho líder al tema, se necesitó indagar en las diversas formas y vías en las que expresa su pensamiento no ajustado a un paradigma determinado, sino que contiene declaraciones y respuestas emergidas de la práctica política directa. La confianza política en el pensamiento de Fidel Castro Ruz asume diversas dimensiones, en tanto se proyecta hacia diversos objetos, individuales y colectivos, que conforman el sistema político instaurado en la nación cubana desde el triunfo de la Revolución: la dirigencia política del proceso; las instituciones revolucionarias, tanto de la sociedad civil como de la sociedad política; los múltiples procesos sociopolíticos que se acometen, entre otros.

Es cierto que en el pensamiento de Fidel se encuentra una gran dosis de confianza en sí mismo, de hecho se reconoce como un "(...) hombre de fe, confianza, optimismo" (Castro, 1985c, p. 102). En su caso, la confianza se proyecta como actitud de un revolucionario hacia la vida, en la certeza de las potencialidades humanas $y$ de los pueblos para la transformación social. Por eso afirma: “(...) el más terrible vicio que se puede apoderar de la conciencia de los hombres $y$ de los pueblos, es la falta de fe y la falta de confianza en sí mismo" (Castro, 1959b, p. 573).

Este asunto deviene un continuo en toda su obra, manifestado tanto en la táctica como en la estrategia para tomar el poder $y$ ulteriormente para mantenerlo; por cuanto, la confianza política expresa la unidad, así como, el nivel de cohesión y asociatividad alcanzados por las fuerzas revolucionarias en la lucha política. La confianza política, al resultar causa y consecuencia de relaciones políticas de interdependencia entre gobernantes y gobernados, del pueblo en sus dirigentes $y$ viceversa, deviene condición sine qua non para la estabilidad y trascendencia en el tiempo de la Revolución Cubana.

\section{LA CONFIANZA POLÍTICA: SU IMPORTANCIA PARA TOMAR EL PODER}

Fidel Castro Ruz emerge como líder revolucionario a nivel nacional, cuando logra establecer una estrategia de lucha política efectiva para enfrentar el estado de cosas impuesto en su nación por Fulgencio Batista y sus seguidores, a partir del 10 de marzo de 1952, mediante un golpe de Estado que anuló los vestigios de democracia representativa instaurados y afianzó la desconfianza política de las masas en los actores del entramado político gobernante (Fung, 1982).

Fidel, a pocas horas del golpe, examina la falta de legitimidad de este, toma como base la 
racionalidad moral, doctrinal, social y política en el análisis de este. El análisis asume la especificidad política fundamental: la cuestión del procedimiento utilizado para acceder al poder, junto a la posible conducta en su utilización y la fuente de autoridad; con ello persigue suscitar un comportamiento de oposición política popular frente al golpe de Estado de Batista (Castro, 1952).

En el artículo jRevolución no, zarpazo!, el líder cubano antagoniza con los políticos tradicionales, sus métodos de hacer política y de traicionar a las masas populares. De este modo, caracteriza el estado real de la política para que estas masas adquirieran conciencia de clase en contra de la nula confiabilidad del régimen político de facto, cuyos fundamentos, procedimientos, normas y métodos no coincidían con las expectativas de la mayoría de la ciudadanía.

Fidel comprendió que la cuestión política a despejar no concernía a la alternancia en el poder, sino al contenido, medios $y$ fines de la política en función de los intereses y necesidades de los humildes, del pueblo; por ello afirma: "(...) Nosotros no vemos la política como la ven los políticos al uso. No nos importan los beneficios personales sino los beneficios del pueblo (...) Si queremos el poder es como medio y no como un fin en sí mismo (...)" (Castro, 1955, p. 87).

Para la lucha política, Fidel Castro le otorga al apoyo del pueblo un rol determinante, por ello, desde los primeros momentos en que decide luchar por tomar el poder político tuvo que definirlo a partir de su contenido popular, de las masas y sectores humildes $y$ trabajadores que lo forman, necesitados de una transformación social y política afín a sus intereses legítimos:

(...) Cuando hablamos de pueblo no entendemos por tal a los sectores acomodados y conservadores de la nación, a los que viene bien cualquier régimen de opresión, cualquier dictadura, cualquier despotismo, postrándose ante el amo de turno hasta romperse la frente contra el suelo. Entendemos por pueblo, cuando hablamos de lucha, la gran masa irredenta, a la que todos ofrecen $y$ a la que todos engañan y traicionan, la que anhela una patria mejor y más digna y más justa; la que está movida por ansias ancestrales de justicia por haber padecido la injusticia y la burla generación tras generación, la que ansía grandes y sabias transformaciones en todos los órdenes y está dispuesta a dar para lograrlo, cuando crea en algo o en alguien, sobre todo cuando crea suficientemente en sí misma, hasta la última gota de sangre (...) (Castro, 1953a, p. 44).

Fidel aporta los factores necesarios para que el pueblo se convierta en protagonista, gane confianza en sí mismo y conquiste el poder político, por cuanto, las masas estarían dispuestas a dar hasta la última gota de sangre solo: a) cuando creyeran en algo o en alguien $y$ b) cuando creyeran suficientemente en sí mismas.

El revolucionario cubano señala dos objetos de la confianza, en ese "algo" subyace implícitamente la revolución, como mediación imprescindible entre el pueblo y su agente político para el cambio del estado de cosas imperante; $y$, en el "alguien", el agente político que conduce a las masas hacia la construcción de un nuevo Estado.

La referencia a "cuando creyeran suficientemente en sí mismas" identifica el proceso de configuración de la conciencia de clase de los diferentes sectores $y$ clases que componen el pueblo, paso previo para que llegue a confiar en sus propias potencialidades, gane conciencia de sus posibilidades y capacidad para convertirse en sujeto histórico y político. Descubre la posible conducta política, el carácter, la orientación $y$ los procedimientos de las masas.

La tarea de rescatar la confianza de las masas en sí mismas, en su papel activo para la lucha política, resulta una labor primaria que se propone Fidel Castro. Esta labor tiene un carácter procesal y contradictorio, en tanto debe ser por etapas, nunca proponerle a las masas populares metas para las que no están preparadas. Además, posee carácter contradictorio porque los enemigos del pueblo tratan de 
sembrar en este dudas, descontento y desconfianza en sus fuerzas $y$ capacidad como sujeto histórico; mientras que las fuerzas revolucionarias tienen, mediante la obra concreta y su comportamiento político y social, que desarrollar y reproducir la confianza política mutua de forma sistemática.

El terreno de los hechos y de una ejecutoria clara, de principios y comprometida; leal a los intereses y metas popularmente legitimados resulta estratégico para las fuerzas revolucionarias, por ello sostuvo:

(...) La primera condición de la sinceridad y de la buena fe en un propósito, es hacer precisamente lo que nadie hace, es decir, hablar con entera claridad $y$ sin miedo. Los demagogos y políticos de profesión quieren obrar el milagro de estar bien en todo y con todos, engañando necesariamente a todos en todo. Los revolucionarios han de proclamar sus ideas valientemente, definir sus principios y expresar sus intenciones para que nadie se engañe, ni amigos ni enemigos (Castro, 1953a, pp. 44-45).

La política revolucionaria, antes de tomar el poder, crea una nueva lógica en la consecuencia medios-fines: tiene que estar en función del avance social y ejecutarse basada en determinados principios; el nexo política-moral deviene esencial, por eso Fidel plantea:

El porvenir de la nación y la solución de sus problemas no pueden seguir dependiendo del interés egoísta de una docena de financieros, de los fríos cálculos sobre ganancias que tracen en sus despachos de aire acondicionado diez o doce magnates (...) Los problemas de la República solo tienen solución si nos dedicamos a luchar por ella con la misma energía, honradez y patriotismo que invirtieron nuestros libertadores en crearla (...) en el mundo actual ningún problema social se resuelve por generación espontánea (Castro, 1953a, pp. 51-52).
En el discurso de autodefensa pronunciado por Fidel Castro Ruz, cuando era sometido a juicio el 16 de octubre de 1953 en Santiago de Cuba, por el asalto al cuartel Moncada publicado como libro con el nombre de La historia me absolverá, adelanta lo que haría el gobierno revolucionario, una vez tomado el poder, con lo que crea confianza en las fuerzas revolucionarias $y$ en su capacidad para satisfacer las demandas de los sectores populares y excluidos:

Un gobierno revolucionario con el respaldo del pueblo y el respeto de la nación después de limpiar las instituciones de funcionarios venales y corrompidos procedería inmediatamente a resolver los problemas del pueblo: el de la tierra, el de la industrialización, el de la vivienda, el del desempleo, el de la educación y el de la salud, junto con la conquista de las libertades públicas y la democracia política (Castro, 1953a, p. 48).

Ante la actitud quietista de muchos que se debatían entre el putsch o la revolución, al sostener que no todas las condiciones estaban creadas para hacer la revolución, devela la proyección política del Movimiento 26 de Julio y explicita con qué fuerzas cuenta este movimiento para lograr sus objetivos: las masas, a las que había que orientar y movilizar. Define, de forma definitiva, su confianza en el pueblo y toma como indicadores que la fundamentan las virtudes que este posee, junto a elementos materiales $y$ espirituales, lo que se evidencia cuando expresa: “(...) ¿quiénes han dado en Cuba prueba de mayor fe en las masas del pueblo, en su amor a la libertad, en su repudio a la Dictadura, en su desesperada miseria y en su conciencia madura? (...)" (Castro, 1953b, p.287).

La confianza del pueblo como factor necesario para el triunfo de la revolución resulta un elemento fundamental en el pensamiento político de Fidel. Fija como tareas inmediatas: movilizar a favor del Movimiento la opinión pública, divulgar las ideas y ganar el respaldo de las masas; identificar el programa, la línea política definida y el prestigio de los revolucionarios como fuentes de confianza del pueblo con fines políticos: “(...) Nuestro programa 
revolucionario es el más completo, nuestra línea la más clara, nuestra historia la más sacrificada: tenemos derecho a ganarnos la fe del pueblo, sin la cual, lo repito mil veces, no hay revolución posible" (Castro, 1954, p. 131).

Pero el pensamiento de Fidel Castro no solo contiene formulaciones que denotan la sustantividad de la confianza política para tomar el poder político en medio de una lucha tenaz contra fuerzas más poderosas en todos los órdenes, sino que cuenta con una riqueza respecto a su significación para mantener el poder político; cuestión que será abordada en las notas que siguen.

\section{LA CONFIANZA POLÍTICA DESDE EL PODER POLÍTICO}

Una vez tomado el poder, el 1ro de enero de 1959, Fidel Castro realiza una ruptura con las formas de pensar $y$ hacer política, tradicionalmente establecidas en su nación; asunto que demandó el cumplimiento práctico de las promesas hechas en La historia me absolverá. La política alcanzaba un nuevo contenido: instrumento para alcanzar la emancipación humana mediante hechos y realidades concretas: “(...) la fe de los pueblos no se despierta con promesas, con teorías, ni con retórica: la fe de los pueblos se despierta con hechos, con realidades, con soluciones verdaderas (...)" (Castro, 1959b, p. 573).

Fidel Castro, en el poder, mantiene un comportamiento consecuente con los fundamentos ideológicos que proclamó cuando inicia la lucha política y asume una práctica política de servicio al pueblo, tal como la concibió el Maestro de todos los cubanos, José Martí: “(...) la política comunitaria, al servicio de la colectividad, el arte de servir al pueblo (...)" (Castro, 1959a).

En este sentido, la búsqueda del apoyo popular se vuelve estratégico como base de sustentación y legitimidad del sistema político y social, debido a que la participación del pueblo en el conjunto de transformaciones resulta decisorio para el avance de los cambios, dado que “(...) el poder no se basa en la fuerza... se basa en el apoyo y el consenso del pueblo..." (Castro, 1991, p. 36).
Consecuentemente, la confianza política de Fidel tiene su base en la convicción del papel de sujeto social y político del ser humano: “(...) Parte todo de una fe, la fe en el hombre, y si existe la fe en el hombre, entonces se tiene la convicción de que no existen sueños ni utopías que no puedan realizarse" (Castro, 1999b, p. 2). Pero dicha confianza no es resultado abstracto, sino consecuencia de fundamentos morales, políticos, socioclasistas y socioeconómicos.

Entre los fundamentos morales, Fidel Castro considera vital el que "(...) nunca se le haya dicho una mentira al pueblo (...)" (Castro, 1985b, pp. 58-59). Este elemento no solo es valorado como fuente de confianza en los seguidores de la Revolución — según Fidelsino hasta por sus adversarios políticos e ideológicos fuera de la nación, por cuanto el hábito de no mentir se convierte en una tradición que viene desde la insurrección armada y que otorga seguridad de que la Revolución Cubana cumple con la palabra empeñada. Además, aporta credibilidad en la información revolucionaria por su carácter objetivo.

El desarrollo del nexo entre moral y política para el alcance de la confianza, en el caso cubano, prefigura la articulación del discurso con la ejecución práctica de lo formulado, lo que determina la identidad distintiva de la práctica política revolucionaria frente a la opinión pública y las acciones abiertas y encubiertas de los enemigos políticos. Asimismo, la autoridad reposa en la moral legitimada por las masas y no en los poderes imperativos de las normas y las prerrogativas formales. La verdad históricamente sostenida consolida la confianza política de las masas populares en la Revolución, sus procesos, autoridades y líderes:

Al pueblo no se le puede decir mentiras; preferible es no publicar una cifra, preferible es no dar una noticia a decir una mentira.

(...) Esa fue la línea y la política que siguió el Gobierno Revolucionario, porque si teníamos un derecho, por qué íbamos a acudir a explicaciones o mentiras. Y fue esa siempre la posición del 
Gobierno Revolucionario. De ahí la fe y la confianza que las masas tienen en la palabra de la Revolución, porque saben que esa es la línea, esa es la tradición (Castro, 1965).

El líder cubano privilegia la actuación política consecuente con las perspectivas suscitadas en la población, una vez asumido el poder político, por lo que frente a hechos de traición dentro de la dirigencia política (ejemplo: los casos de Hubert Matos y Arnaldo Ochoa), defiende el proceder resuelto $y$ comprometido hasta las últimas consecuencias a favor del pueblo; lo que constituye un factor que posibilita la generación de la confianza política. Asunto que evidencia la lealtad a los sectores y grupos más humildes, a los de abajo en sus demandas y aspiraciones, ya que el actuar consecuente basado en principios éticos define la condición de revolucionarios. En el caso del proceso judicial realizado a Hubert Matos, quien planteara que los dirigentes de la Revolución habían engañado al pueblo, por lo cual Fidel Castro afirma durante su intervención:

Yo creo sencillamente que nosotros aquí, en el Gobierno Revolucionario, no hemos hecho más que cumplir con lo que prometimos al pueblo.

(...) La Revolución dijo a dónde iba, desde mucho antes de que nosotros llegáramos a la playa de Belice.

...Nuestra conducta, nuestra postura, nuestros planteamientos, cómo hemos actuado; si nosotros hemos sido unos mentirosos engañadores del pueblo, o nosotros hemos sido hombres que siempre hemos dicho la verdad (...). No hemos más que cumplir lo que prometimos al pueblo (Castro, 1959c, p. 298).

Para el caso de Arnaldo Ochoa, un alto dirigente procesado en 1989 por estar vinculado al tráfico internacional de drogas, entre otras causas, Castro sostiene:
... cuando hay un deterioro moral se pierde la base ética, $y$ cuando esta base se pierde, cuando se han perdido los principios fundamentales, no se puede confiar en nadie, porque un revolucionario es revolucionario en virtud de ciertos principios, es revolucionario en virtud de una ética (Castro, 1989b, p.41).

Dentro de los fundamentos políticos que sustentan la confianza, reconoce: la identificación entre el Estado y el ciudadano (Castro, 1985a); la obra revolucionaria desarrollada, de manera tangible, en todas las esferas de la vida social (Castro, 1989a); la unidad del pueblo expresada en la profunda identificación entre el pueblo, los dirigentes y las diferentes instituciones (Castro, 1990); el consenso del pueblo, la conciencia que tiene este de lo que fue el país y de lo que no puede volver a ser jamás (Castro, 1995).

Además, otro fundamento político resulta la interrelación entre el líder y el pueblo. Fidel defiende la idea de las necesarias interrelaciones entre ambos y expone su criterio del papel decisivo del pueblo para el avance del proceso revolucionario y la ejecución gubernamental efectiva, es por eso que sostiene:

En Occidente hay la tendencia a atribuirles a los hombres los méritos de los proceso políticos y dicen: 'La Cuba de Castro', 'El gobierno de Castro', cuando es la Cuba de todo un pueblo, el gobierno de un pueblo, la obra de un pueblo; se suele atribuir a los individuos méritos que no puede tener ningún dirigente (Castro, 1991, p. 19-20).

Desde el pensamiento político del líder cubano, el alcance de la confianza política está determinado, en gran medida, porque la conducción política del proceso revolucionario representa y expresa las ideas de la mayoría de la población:

Esa ha sido hasta hoy y será siempre nuestra conducta futura, porque confiamos en el pueblo (...) Las ideas que aquí cualquiera de nosotros exprese no son 
simplemente sus ideas, son las ideas de millones y millones de personas, de la inmensa mayoría, de la casi totalidad del pueblo (Castro, 2001, p.6).

Para Fidel Castro, la claridad en la estrategia y la táctica, junto a las opciones y posibles variantes es otro factor que influye en el alcance de la confianza política (Castro, 1989a). Este fundamento pone a prueba la capacidad pronosticadora, decisoria y prospectiva de la dirigencia política en tanto los reajustes sociales, económicos y políticos implementados deben buscar la lógica de gobernabilidad afín al carácter popular del proceso. Las estrategias no deben concebirse sobre la base de supuestos abstractos, sino a partir de sistemáticos diagnósticos que impliquen a la totalidad de la población y que reconstruyan el consenso, por cuanto, la unidad es base decisiva para obtener el apoyo del pueblo, reproducir la legitimidad del poder y de la existencia misma de la Revolución Cubana.

La confianza política en el pensamiento de Fidel Castro, se articula con las posibilidades de continuidad del proceso revolucionario, no señala metas ni fórmulas preestablecidas, pero sí presupone que la garantía está en el accionar de los sujetos revolucionarios, que ubica tanto en la sociedad civil como en la sociedad política al interior del sistema político por la imposibilidad de que algún agente externo o individuo pueda derrumbar dicho sistema; asunto que exterioriza en el Aula Magna de la Universidad de La Habana, el 17 de noviembre de 2005.

Fidel en ese discurso formuló varias interrogantes, entre ellas: "¿Creen ustedes que este proceso revolucionario, socialista, puede 0 no derrumbarse? ¿Lo han pensado alguna vez? ¿Lo pensaron en profundidad?” (Castro, 2005). Estas preguntas cuestionan un asunto estratégico: las condiciones de posibilidad de la continuidad en el poder de la Revolución Cubana, es decir, su trascendencia política e histórica. Aspecto que articula con el potencial crítico de todos los actores implicados, la participación real en la definición de la agenda política y la búsqueda de soluciones a los problemas del desarrollo, la democratización de la sociedad, la movilización y la lucha contra las múltiples formas que frenan $y$ se contraponen, desde afuera $y$ desde dentro del aparato de dirección, al cumplimiento de los objetivos revolucionarios.

Las múltiples formas que frenan el desarrollo revolucionario: corrupción, deslealtad, traición, demagogia, engaño, robo, nepotismo; asumen modos de actuación negativos que erosionan la propiedad social y socavan los fundamentos ideológicos y políticos del poder revolucionario, por cuanto subvierten las disposiciones legales, la naturaleza de las relaciones consustanciales a la sociedad socialista, el papel del trabajo, los soportes éticos y la confianza entre gobernantes y gobernados. Para alcanzar un enfrentamiento organizado $y$ eficaz debe asumirse el método de masas, promulgado por Fidel Castro por su papel estratégico y democrático, junto a la necesaria vinculación entre la legalidad-legitimidad.

El líder cubano relaciona los fundamentos socioclasistas con los actores sociales que, tienen "razones para apoyar a la Revolución"; en primer lugar, los identifica por el contenido clasista de la inmensa mayoría que conforma la población, los trabajadores: obreros y campesinos, manuales e intelectuales; luego hace un análisis cuantitativo en cuanto a género y señala a las mujeres, por constituir la mitad de la población, sean trabajadoras o amas de casa; de la proporción étnica toma como referente a la población negra del país; hasta llegar a la cuestión etaria, incluye a los estudiantes y la juventud (Castro, 1985b). Fidel utiliza como indicadores para mostrar la objetividad de estas "razones" la obra material y social realizada por la Revolución en beneficio de estos grupos, sectores y clases sociales.

Para exponer los fundamentos socioeconómicos, Fidel Castro tiene presente la obra de la Revolución, el conjunto de problemas sociales, políticos, materiales y de toda clase resueltos a una población que no era objeto de ninguna consideración por los gobernantes en el pasado. La experiencia política trasmitida de generación en generación, emplea como indicadores, los avances en la educación, la salud pública, los niveles de alimentación, la seguridad social, el nivel y calidad de vida de la 
población, la cultura, la transformación de las ciudades del interior de la nación, entre otros (Castro, 1985b).

Por otra parte, en la definición de Revolución, dada por Castro (2000), se encuentran las claves para determinar otras fuentes de la confianza política en el contexto cubano:

Revolución es sentido del momento histórico; es cambiar todo lo que debe ser cambiado; es igualdad y libertad plenas; es ser tratado y tratar a los demás como seres humanos; es emanciparnos por nosotros mismos $y$ con nuestros propios esfuerzos; es desafiar poderosas fuerzas dominantes dentro $y$ fuera del ámbito social y nacional; es defender valores en los que se cree al precio de cualquier sacrificio; es modestia, desinterés, altruismo, solidaridad y heroísmo; es luchar con audacia, inteligencia y realismo; es no mentir jamás ni violar principios éticos; es convicción profunda de que no existe fuerza en el mundo capaz de aplastar la fuerza de la verdad y las ideas. Revolución es unidad, es independencia, es luchar por nuestros sueños de justicia para Cuba $y$ para el mundo, que es la base de nuestro patriotismo, nuestro socialismo $y$ nuestro internacionalismo.

La definición, antes citada, codifica el comportamiento seguido por la Revolución Cubana en su lucha, a lo largo de más de cuatro décadas, frente al Estado y los sucesivos gobiernos de Estados Unidos, potencia que asume el carácter unipolar y hegemónico, desde finales de los años 80 hasta hoy. En esta tesis, Fidel Castro organiza los factores orgánicos efectivos que han contribuido al objetivo político de mantener la estabilidad $y$ la gobernabilidad revolucionaria en diferentes circunstancias, aun frente al hostil impacto que significó el desplome del campo socialista europeo, y que guiaron la paulatina recuperación ulterior.

Esta definición orienta dos criterios determinantes para la política revolucionaria: a) el comportamiento análogo de los sujetos del cambio, libre de dogmatismo, esquematismo $y$ quietismo quienes obran con iniciativa creadora y plena confianza en sí mismos cuando asumen el liderazgo en las transformaciones que se acometen; b) el fundamento de la legitimidad: una política humanista que persigue la emancipación basada en la igualdad y la libertad plenas.

Para reproducir la confianza política, la política revolucionaria resulta un medio esencial de la dignificación humana en su sentido amplio y pleno, a través de la Revolución con su obra tangible:

... la política, es decir, la Revolución, es el instrumento de la educación, de la cultura, del deporte, de los valores humanos, de los valores espirituales (...) Porque la Revolución se hace para eso, sencillamente por el hombre, para el bien del hombre - ese es su objetivo- $y$ todo lo que de una manera o de otra pueda contribuir al bienestar $y$ a la felicidad del hombre en el orden espiritual, en el orden moral, en el orden material, en el orden social, es decir, en todos los órdenes (Castro, 1971).

En la tabla 1, se muestran una serie de logros alcanzados por Cuba hasta el año 2015, previo a la salida del poder de Fidel Castro: 
TABLA 1

LOGROS COMPARATIVOS DE CUBA RESPECTO A AMÉRICA LATINA HASTA ABRIL DE 2015

\begin{tabular}{lcc}
\hline INDICADOR & AMÉRICA LATINA & CUBA \\
\hline Tasa de analfabetismo & $11,7 \%$ & $0,2 \%$ \\
$\begin{array}{l}\text { Tasa de escolarización en la enseñanza primaria } \\
\text { (hasta los } 11 \text { años) }\end{array}$ & $92 \%$ & $100 \%$ \\
$\begin{array}{l}\text { Tasa de escolarización en la enseñanza secundaria } \\
\text { (hasta los } 14 \text { años) }\end{array}$ & $52 \%$ & $99,7 \%$ \\
Niños que alcanzan el nivel de colegio & $76 \%$ & $100 \%$ \\
Mortalidad infantil & 32 por cada mil nacidos vivos & 4,6 por cada mil nacidos vivos \\
Esperanza de vida & 70 años & 78 años \\
Número de médicos por 100 000 habitantes & 160 & 590 \\
Tasa de desempleo & $11 \%$ & $1,9 \%$ \\
Acceso a la seguridad social & $45 \%$ de los habitantes.
\end{tabular}

Fuente: $\quad$ Lamrani, S. (10/04/2015).

Otro logro alcanzado por la Revolución Cubana es la disminución progresiva de la tasa de mortalidad infantil, indicador que muestra la atención a la salud pública de la población en general $y$, especialmente, a la madre y el niño.
A este asunto, Fidel Castro, lo puso en el centro de atención de su actividad política; el comportamiento histórico de dicho indicador se muestra en la tabla 2:

TABLA 2

RESULTADOS HISTÓRICOS DE CUBA EN LA TASA DE MORTALIDAD INFANTIL (POR 1000 NACIDOS VIVOS)

\begin{tabular}{lc}
\hline INDICADOR TEMPORAL & TASA DE MORTALIDAD \\
\hline Década de los años 60 & 34,8 \\
Década de los 70 & 19,4 \\
Década de los 80 & 11,1 \\
Década de los 90 & 6,5 \\
Primera década del siglo xxI & 4,7 \\
2011 & 4,9 \\
2012 & 4,6 \\
2013 & 4,2 \\
2014 & 4,2 \\
2015 & 4,3 \\
2016 & 4,3 \\
\hline
\end{tabular}

Fuentes: Castro Pacheco (2016) y Ministerio de Salud Pública de la República de Cuba, Dirección de Registros Médicos y Estadísticas de Salud (2017). 


\section{NOTAS CONCLUSIVAS}

Durante los últimos 50 años, el análisis de la confianza política ha devenido un área de estudio significativa para las ciencias sociales, especialmente para la ciencia política. En este marco ha prevalecido un enfoque liberal del asunto donde predomina una visión descriptiva $y$ abstracta que limita las posibilidades heurísticas de esta confianza. El insuficiente tratamiento de la confianza política demanda nuevas irrupciones desde otras perspectivas para universalizar la pluralidad de enfoques respecto a la confianza política.

En el pensamiento de Fidel Castro existen formulaciones novedosas que contribuyen a la construcción de un enfoque Sur de la confianza política, esta se enfoca como uno de los factores subjetivos imprescindibles para la lucha política no solo para acceder al poder político sino para mantenerlo. Al analizar estas formulaciones puede asumirse que la confianza política está configurada por tres componentes básicos: cognoscitivo, afectivo $y$ valorativo-conductual, los que se integran $y$ articulan como un todo.

La confianza política, desde este pensamiento, asume diversas dimensiones en tanto se proyecta hacia diversos objetos, individuales y colectivos, que conforman el sistema político de la Revolución Cubana: la dirigencia política, las instituciones revolucionarias, tanto de la sociedad civil como de la sociedad política, los múltiples procesos sociopolíticos que se acometen. Este asunto expresa la unidad y el nivel de cohesión y asociatividad alcanzados por las fuerzas revolucionarias en la lucha política, especialmente entre el líder y el pueblo.

Para Fidel Castro, la claridad en la estrategia y la táctica, junto a las opciones, posibles variantes, las posibilidades de continuidad del proceso revolucionario junto a fundamentos socioclasistas y socioeconómicos resultan factores que influyen en el alcance de la confianza política. Por el contrario, las múltiples formas que frenan el desarrollo revolucionario: corrupción, deslealtad, traición, demagogia, engaño, robo, nepotismo subvierten las disposiciones legales, la naturaleza de las relaciones consustanciales a la sociedad socialista, el papel del trabajo, los soportes éticos y la confianza entre gobernantes y gobernados.

Hoy, la confianza política resulta definitoria para el avance y estabilidad de la Revolución Cubana, los procesos de cambio en el modelo económico-social, jurídico y estatal junto con el anhelado pero hasta ahora no conseguido despunte económico-financiero generan resistencias, preocupaciones $y$ dudas en algunos grupos e individuos en medio de la escalada en la guerra económica, financiera y mediática de los Estados Unidos contra el pueblo cubano. En este difícil contexto resulta estratégico tener en cuenta las formulaciones contenidas en el pensamiento de Fidel Castro que contribuyen a un nuevo enfoque de la confianza política.

\section{REFERENCIAS}

Braun, D. y Hutter, S. (2016). Political trust, extra-representational participation and the openness of political systems. International Political Science Review, 37 (2), 151-165.

Castro Pacheco, B. (2016). Evolución de la mortalidad infantil en Cuba. Revista Cubana de Pediatría, 88 (1). Recuperado de http:// www.revpediatria.sld.cu/index.php/ped/ article/view/38/20.

Castro Ruz, F. (16/08/1952). ¡Revolución no, zarpazo! El Acusador. En Castro Ruz, F. (2007). Fidel Castro. Selección de documentos, entrevistas y artículos (19521956) (pp. 1-3). La Habana, Cuba: Editora Política.

Castro Ruz, F. (1953a). Discurso ante la Sala Primera de Urgencia de la Audiencia de Santiago de Cuba. En Álvarez Tabío, P. y Alonso Fiel, G. (Eds.). (2005). La Historia me Absolverá. Edición anotada. La Habana, Cuba: Oficina de Publicaciones del Consejo de Estado.

Castro Ruz, F. (1953 b). Mensaje a Cuba que sufre. En La Revolución Cubana. 19531980. Selección de Lecturas 1. Primera Parte (pp. 284-288). Ciudad de La Habana, Cuba: Editorial Pueblo y Educación.

Castro Ruz, F. (1954). Carta a Melba y Haydée, 19 de junio de 1954. En M. Mencia. 
(1980). La prisión fecunda (pp. 131). La Habana, Cuba: Editora Política.

Castro Ruz, F. (1955). Manifiesto nro.1 del 26 de julio al pueblo de Cuba. En F. Castro. (2007). Fidel Castro: Selección de documentos, entrevistas y artículos (19521956) (pp. 82-95). La Habana, Cuba: Editora Política.

Castro Ruz, F. (1959a). Discurso en la plaza de la ciudad de Camagüey, el 4 de enero. Recuperado de http://www.cuba.cu/ gobierno/discursos/1959/esp/f040159e. html

Castro Ruz, F. (1959b). Discurso pronunciado en la Sexta Sesión Plenaria de la Reunión de los 21, en Buenos Aires, Argentina, 2 de mayo. En F. Castro Ruz. (1983). El pensamiento de Fidel Castro. Selección temática (v. 2, t.1). La Habana, Cuba: Editora Política.

Castro Ruz, F. (1959c). Fragmento de las declaraciones en el juicio contra el ex comandante Hubert Matos, en Ciudad Libertad, 14 de diciembre de 1959. En J. Bell Lara et ál. (2006). Documentos de la Revolución cubana 1959 (pp. 298-314). Ciudad de La Habana, Cuba: Editorial de Ciencias Sociales.

Castro Ruz, F. (1965). Discurso pronunciado en el IV aniversario de la fundación del Ministerio del Interior, celebrado en el teatro "Chaplin", 16 de junio. Recuperado de http://www.cuba.cu/gobierno/discursos/1965/f160665html

Castro Ruz, F. (1971). Discurso pronunciado en el resumen del acto homenaje a los atletas de la delegación deportiva cubana que asistió a los vi Juegos Panamericanos de Cali, Colombia, efectuado en la Ciudad Deportiva, 14 de agosto. Recuperado de http://www.cuba.cu/gobierno/discursos/1971/esp/f140871e.html

Castro Ruz, F. (1975). Informe del Comité Central del PCC al Primer Congreso. La Habana, Cuba: Departamento de Orientación Revolucionaria del Comité Central del Partido Comunista de Cuba.

Castro Ruz, F. (1985a). Discurso en el vil período ordinario de sesiones de la Asamblea
Nacional del Poder Popular. Granma, Suplemento Especial.

Castro Ruz, F. (1985b). Nada podrá detener la marcha de la historia. La Habana, Cuba: Editora Política.

Castro Ruz, F. (1985c). Fidel y la religión. Conversaciones con Frei Betto. La Habana, Cuba: Oficina de Publicaciones del Consejo de Estado.

Castro Ruz, F. (1989a). Socialismo ciencia del ejemplo. La Habana, Cuba: Editora Política.

Castro Ruz, F. (1989b). Intervención en la reunión del Consejo de Estado, en relación con la Causa nro.1 de 1989. En F. Castro Ruz. Discursos. Documentos. Ediciones OR (2). La Habana, Cuba: Oficina de Publicaciones del Consejo de Estado.

Castro Ruz, F. (1990). Discurso pronunciado el $1^{\circ}$ de febrero de 1990 en el acto de recibimiento a la tripulación del buque "Hermann" en Ciudad de La Habana. En F. Castro Ruz. En la trinchera de la Revolución (pp. 77-93). La Habana, Cuba: Editorial José Martí.

Castro Ruz, F. (1991). Presente y futuro de Cuba. La Habana, Cuba: Oficina de Publicaciones del Consejo de Estado.

Castro Ruz, F. (1995). Discurso con motivo del inicio del curso escolar 1995/96 y sus 50 años de vida revolucionaria, iniciada en la Facultad de Derecho, efectuado en el Aula Magna de la Universidad de La Habana, 4 de septiembre. Recuperado de http://www.cuba.cu/gobierno/discursos/1995/esp/f040995e.html

Castro Ruz, F. (1999a). Discurso pronunciado en el Aula Magna de la Universidad Central de Venezuela, el 3 de febrero. En F. Castro Ruz. Una Revolución solo puede ser hija de la cultura y las ideas. La Habana, Cuba: Editora Política.

Castro Ruz, F. (1999b, noviembre, 27). Discurso pronunciado en la clausura del viII Congreso de la Federación Latinoamericana de Periodistas (FELAP), 12 de noviembre. Granma, Suplemento Especial, 2. 
Castro Ruz, F. (2000). Discurso pronunciado en la Tribuna Abierta de la Juventud, los Estudiantes y los Trabajadores por el Día Internacional de los Trabajadores, en la Plaza de la Revolución, el Primero de Mayo. Recuperado de http://www. cuba.cu/gobierno/discursos/2000/esp/ f010500e.html

Castro Ruz, F. (28/02/2001). Discurso pronunciado en la conmemoración del 40 aniversario del INDER $y$ en la inauguración de la Escuela Internacional de Educación Física y Deportes. Granma, 4-6.

Castro Ruz, F. (2005). Discurso pronunciado en el acto por el aniversario 60 de su ingreso a la universidad, efectuado en el Aula Magna de la Universidad de La Habana, 17 de noviembre. Recuperado de http:// www.cuba.cu/gobierno/discursos/2005/ esp/f171105e.html

Catterberg, G. y Moreno, A. (2003). The Individual Bases of Political Trust: Trends in New and Established Democracies. International Journal of Public Opinion Research, 18 (1), 31-48.

Dogan, M. (1997). Erosion of Confidence in Advanced Democracies. Studies in Comparative International Development, (32), 3-29.

Fung Riverón, T. (1982). En torno a las Regularidades y Particularidades de la Revolución Socialista en Cuba. La Habana, Cuba: Editorial de Ciencias Sociales.

Hetherington, M. (2009). Why Trust Matters: Declining Political Trust and the Demise of American Liberalism. Recuperado de www.amazon.com/Why-Trust-MattersDeclining-Liberalism/dp/0691117764$173 k$

Hetherington, M. (1999). The Effect of Political Trust on the Presidential Vote, 1968-96. American Political Science Review, 93 (2), 311-326.

Hetherington, M. (1998). The Political Relevance of Political Trust. American Political Science Review, 92 (4), 791-808.

Klingemann, H. (1999). Mapping Political Support in the 1990s: A Global Análisis.
En Pippa Norris (ed.). Critical Citizens: Global Support for Democratic Government (pp. 31-56). Oxford, Reino Unido de Inglaterra: Oxford University Press.

Lamrani, S. (10/04/2015). Fidel Castro reformador social. Granma, 3. Recuperado de http://www.granma.cu/cuba/2015-04-10/ fidel-castro-reformador-social?page $=3$

Marien, S. y Hooghe, M. (2013). A comparative analysis of the relationship between political trust and forms of political participation in Europe. European Societies, 15 (1), 131-152.

Ministerio de Salud Pública de la República de Cuba, Dirección de Registros Médicos y Estadísticas de Salud. (2017). Anuario Estadístico de Salud, p.47. Recuperado de http://files.sld.cu/dne/files/2018/04/ Anuario-Electronico-Espa\%C3\%B1ol2017-ed-2018.pdf

Miller, A. (1974). Rejoinder to "Comment" by Jack Citrin: Political Discontent a Ritualism? American Political Science Review, 68 (3), 989-1001.

Mishler, W. y Rose, R. (2001). What Are the Origins of Political Trust? Testing Institutional and Cultural Theories in Post-Communist Societies. Comparative Political Studies, 34 (1), 30-62.

Montero, J.; Zmerli, S.; Newton, K. (2008). Confianza social, confianza política y satisfacción con la democracia. Revista Española de Investigaciones Sociológicas (REIS), (122), 11-54.

Montero, J. y Torcal M. (2000). La desafección política en España: un legado que condiciona el presente. Revista de Occidente, (227), 15-30.

Newton, K. (2001). Confianza Social y Capital Social: Confianza Política y Capital Político. En Máiz, R. (Ed.). Construcción de Europa, Democracia y Globalización, vol. 2 (pp. 1115-1142). Santiago de Compostela, España: Universidad de Santiago de Compostela, Servicio de Publicaciones e Intercambio Científico.

Norris, P. (2011). Democratic Deficit: Critical Citizens Revisited. Cambridge, Reino 
Unido de Inglaterra: Cambridge University Press.

Schoon, I. y Helen C. (2011). Determinants of Political Trust: A Lifetime Learning Model. Developmental Psychology, 47 (3), 619-631.

Paramio, L. (1998). Clase y voto: intereses, identidades y preferencias. Recuperado de http://www.iesam.csic.es/doctrab1/ dt-9812.htm

Poppe, J. (2004). Political Trust and Religion. CHARIS: A Journal of Lutheran Scholarship, Thought, and Opinion, 4, 27-42.

Putnam, R. (2000). Bowling Alone. The Collapse and Revival of American Community. New York, Estados Unidos de América: Simon and Schuster.

Rudolph, T. y Evans J. (2005). Political Trust, Ideology, and Public Support for Government Spending. American Journal of Political Science, 49 (3), 660-671.
Verdecia Tamayo, M. (2010). Un punto de vista acerca de la confianza política en el pensamiento de Fidel Castro. Revista Cubana de Ciencias Sociales, (43), 22-44.

Warren, M. (Ed.) (1999). Democracy and Trust. Cambridge, Reino Unido de Inglaterra: Cambridge University Press.

Wilson, R. y Eckel C. (2006). Judging a Book by its Cover: Beauty and Expectations in the Trust Game. Political Research Quarterly, 59 (2), 180-191.

Zmerli, S. y van der Meer, T. (Eds.). (2017). Handbook on Polítical Trust. University of Amsterdam, Holanda: Edward Elgar Publishing.

Fecha de ingreso: 13/09/2018 Fecha de aprobación: 20/05/2019 
